\title{
Capsule Commentary on Schonberg et al., Older Women's Experience with a Benign Breast Biopsy-A Mixed Methods Study
}

\author{
Sara L. Jackson, MD MPH \\ Division of General Internal Medicine, University of Washington, Seattle, WA, USA.
}

J Gen Intern Med 29(12): 1689

DOI: $10.1007 / \mathrm{s} 11606-014-2997-4$

(c) Society of General Internal Medicine 2014

$\mathrm{W}$ omen 65 years and older are commonly screened for breast cancer with mammography. Models estimate that screening 1,000 women biannually for 10 years after the age of 69 would result in two fewer cancer deaths, 200 false positive mammograms, and 13 cases of over-diagnosis (breast cancer that would not have been clinically evident otherwise). ${ }^{1}$ The study by Schonberg et al. evaluates the effects of benign breast biopsies upon older women, using validated scales of psychological and physical consequences measured at the time of biopsy and after 6 months, and uses qualitative data to develop a conceptual model of undergoing a benign breast biopsy. ${ }^{2}$

At the time of biopsy, $76 \%$ of women reported negative psychological consequences, which persisted at 6 months for $39 \%$. After 6 months, one in five women felt that worry interfered with their daily activities, and there was a trend for women with $\leq 9$ years life expectancy to have higher negative psychological consequences compared to healthier women. Women also noted competing health issues in the qualitative data, all of which support the need for personalized decision making to balance risks and benefits of breast cancer screening in this age group.

Opportunities identified for optimizing the experience of breast biopsies for women include positive interactions with radiology staff and physicians and systematic processes that minimize the wait time for test results. Women want information that explains biopsy procedures and diagnosis-specific information post-biopsy. Patient education materials would need to reflect current recommendations, ${ }^{3}$ particularly for diagnoses that are associated with higher risk for breast cancer, such as atypia, and to acknowledge the paucity of evidence supporting mortality benefit from such follow-up. Delivering this information via the primary care provider, with whom women wanted to communicate, would improve on-going shared decision making about future breast cancer screening.

Decision aids that personalize screening recommendations based upon women's competing medical issues and life expectancy ${ }^{4,5}$ would ideally be easily accessible in the primary care setting within an electronic medical record. These supports are needed to decrease the harms of breast cancer screening among women 65 years and older.

Conflict of Interest: The author has no conflicts of interest with the material in this article.

Corresponding Author: Sara L. Jackson, MD MPH; Division of General Internal MedicineUniversity of Washington, Seattle, WA, USA (e-mail: sljack@uw.edu).

\section{REFERENCES}

1. Walter LC, Schonberg MA. Screening mammography in older women: a review. JAMA. 2014;311(13): 1336-47.

2. Schonberg MA, Silliman RZ, et al. Older women's experience with a benign breast biopsy-A mixed methods study. JGIM. 2014; etc. (Article SPI \#2981)

3. Neal L, Sandhu NP, Hieken TJ, Glazebrook KN, Mac Bride MB, Dilaveri CA, et al. Diagnosis and management of benign, atypical, and indeterminate breast lesions detected on core needle biopsy. Mayo Clin Proc. 2014;89(4):536-47.

4. Schonberg MA, Hamel MB, Davis RB, Griggs MC, Wee CC, Fagerlin A, et al. Development and evaluation of a decision aid on mammography screening for women 75 years and older. JAMA Int Med. 2014;174 (3):417-24.

5. Lansdorp-Vogelaar I, Gulati R, Mariotto AB, Schechter CB, de Carvalho TM, Knudsen AB, et al. Personalizing age of cancer screening cessation based on comorbid conditions: model estimates of harms and benefits. Ann Intern Med. 2014;161(2):104-12. 